\title{
Evaluation of Influence of Gender, Occupational Injury, and Smoking on Chronic Low Back Pain of Facet Joint Origin: A Subgroup Analysis
}

\author{
Laxmaiah Manchikanti, MD*, Vijay Singh, MD\#, Bert Fellows, MA ${ }^{\Omega}$, and Vidyasagar Pampati, MSc ${ }^{\star *}$
}

The prevalence of persistent low back pain secondary to involvement of lumbosacral facet joints has been described in controlled studies as varying from $15 \%$ to $52 \%$ based on types of population and settings studied. Previous studies have shown variances in elderly populations, and postlumbar laminectomy patients. But no variations were observed in obese patients or patients with somatization disorder. Based on the individual results, it appears that facet joint pain may be less prevalent in patients with occupational injury and more prevalent in women and smokers.

This analysis was based on a combination of the results of two previous studies with a total number of 320 patients to evaluate the influence of gender, occupational injury and smoking on prevalence of facet joint pain. Facet joints were investigated with diagnostic blocks initially using lidocaine $1 \%$, followed by bupivacaine $0.25 \%$, usually 2 to 4 weeks apart in these studies.

Low back pain is a multifactorial disorder with many possible etiologies. Tissues in the lower back capable of transmitting pain include facet joints, discs, nerve root dura, ligaments, muscles, and fascia (1). The existence of facet joint pain, along with its prevalence, has been a topic of controversy in modern medicine. Facet joints meet strict criteria to be capable of producing chronic low back pain, and proven diagnostic criteria exist for the diagnosis of facet joint pain. Bogduk (2) postulated that, for any structure to be deemed a cause of back pain, it should have a nerve supply; should be capable of causing pain similar to that seen clinically, ideally in normal volunteers; should be susceptible to diseases or injuries that are known to be painful; and should have been shown to be a source of

From Pain Management Center of Paducah, Paducah, Kentucky and Pain Diagnostic Associates, Niagara, Wisconsin. *Medical Director, ${ }^{* *}$ statistician, and ${ }^{\Omega}$ psychologist at the Pain Management Center of Paducah. \#Medical Director of Pain Diagnostic Associates. Address correspondence: Laxmaiah Manchikanti, MD, 2831 Lone Oak Road, Paducah, Kentucky 42003. E-mail: drm@ asipp.org
The prevalence of facet joint pain in men was 38\% (95\% CI, $29 \%$ to $47 \%$ ) compared to $43 \%$ (95\% CI, $36 \%$ to $50 \%$ ) in women; $43 \%$ (95\% CI, $33 \%$ to $53 \%$ ) in non-smokers, compared to $41 \%$ ( $95 \%$ CI, $30 \%$ to $52 \%$ ) in heavy smokers; and $28 \%$ ( $95 \% \mathrm{CI}, 18 \%$ to $38 \%$ ) in occupational injury patients compared to $44 \%$ (95\% CI, $36 \%$ to $52 \%$ ) with a history of gradual onset. False-positive rates varied from $28 \%$ to $46 \%$.

In conclusion, based on the results of this evaluation, women and men, smokers and nonsmokers suffer with similar prevalence rates of facet joint pain in chronic low back pain; whereas occupational injury patients suffer with lesser prevalence (28\%) compared to patients with gradual onset (44\%) of low back pain.

Keywords: Chronic low back pain, facet joint pain, controlled diagnostic blocks, comparative local anesthetic blocks, smoking, occupational injury

pain in patients, using diagnostic techniques of known reliability and validity. In 1911, Goldthwait (3) recognized lumbar facet joints as potential sources of back pain. Subsequently, in 1927, the Italian surgeon, Putti (4), published his experiences on articular facet degeneration as a cause of pain, which supported the findings of Goldthwait. The term "facet syndrome" was coined by Ghormley (5) in 1933 defining the specific pattern of low back pain with or without sciatic pain, particularly occurring suddenly after twisting or rotatory strain of the lumbosacral region. In spite of the disc's overshadowing the spine as the causative factor for low back pain, in 1941 Badgley (6) suggested that facet joints themselves could be a primary source of pain separate from the nerve compression component and made a plea for continuing focus on the facets in order to explain the large number of patients with low back pain whose symptoms were not due to a ruptured disc. In 1963, Hirsch et al (7) showed that injection of hypertonic saline in the region of the facet joints produced pain along the sacroiliac and gluteal areas with radiation to the greater trochanter. Subsequently, Mooney and Robertson (8) in 1976, McCall et al (9) in 1979, Marks (10) in 1989, and Fukui et al (11) in 1997 confirmed causation of low back pain and 
its relief describing various pain patterns with injection into facet joints.

The prevalence of persistent low back pain secondary to the involvement of lumbosacral facet joints has been described in controlled studies as varying from $15 \%$ to $52 \%$ based on types of population and settings studied (12-22). Based on the results available thus far, there has been significant variability among different populations, with lower rates reported among adults, injured, and postlumbar laminectomy syndrome sufferers. However, no significant differences were noted among obese and nonobese patients and patients with or without somatization. Based on the available literature, it appears that there may be differences between injured patients compared to the patients with low back pain of gradual onset $(12,18)$. However, the issue has not been evaluated systematically. In addition, it has not been evaluated whether there are any significant differences between men and women and smokers and nonsmokers.

Thus, this evaluation was undertaken to evaluate the effect of gender, occupational injury, and smoking on incidence and prevalence of facet joint pain in patients suffering with chronic low back pain and presenting to interventional pain management settings, by analyzing data from two previous studies $(16,18)$.

\section{METHODS}

This evaluation was designed to combine 320 patients from two studies $(16,18)$. Both studies were designed to evaluate patients with a chief complaint of chronic low back pain, in a nonuniversity setting, in one private comprehensive interventional pain management practice. The first study evaluated 200 consecutive patients (16), whereas the second study (18) evaluated 120 randomly allocated patients. In both studies, patients younger than 18 years or older than 90 years, those who exhibited neurological deficits, those who had pain for less than 6 months, and those who presented with a definite diagnosis based on findings of radiological or neurophysiologic testing were excluded. Evaluation of patients included a comprehensive evaluation with completion of standard, comprehensive pain management questionnaires; history, physical examination, and evaluation of the results of all procedures and investigations. All patients underwent conservative management which included physical therapy, chiropractic treatment, exercises, drug therapy, bedrest, etc., which failed to provide significant improvement. All patients consented and participated in the studies after the nature of the studies and the potential hazards of the procedures were explained to them.

All 320 patients underwent diagnostic blocks using lidocaine $1 \%$, initially followed by bupivacaine $0.25 \%$ on separate occasions, usually 2 to 4 weeks apart. The blocks were performed on the ipsilateral side in patients with unilateral pain or bilaterally in patients with bilateral or axial pain. The blocks were performed with a 22-gauge, 3.5inch spinal needle under intermittent fluoroscopic visualization at each of the medial branches at the L1 through L4 and L5 dorsal ramus. Each nerve was infiltrated with 0.4 to $0.6 \mathrm{~mL}$ of either $1 \%$ lidocaine or $0.25 \%$ bupivacaine with or without adjuvants. Following each block, the patients were examined for pain by having them perform previously painful movements. In order to be considered positive, the response to a block had to last longer than 2 hours when lidocaine was used; and either longer than the duration of effect from lidocaine, or at least 3 hours, when bupivacaine was used.

The combined data were analyzed to evaluate the effect of gender, occupational injury, and smoking on prevalence of facet joint pain in chronic low back pain $(16,18)$. Data were recorded on a database using Microsoft ${ }^{\circledR}$ Access $®$; the SPSS Version 9.0 statistical package was used to generate frequency tables, and the chi-squared statistic was used to test the significant difference between groups. Results were considered statistically significant if the $p$ value was less than .05 .

\section{RESULTS}

\section{Gender}

As shown in Table 1, there were 121 men and 199 women. The prevalence of facet joint pain based on double block paradigm was $38 \%$ (95\% CI, $29 \%$ to $47 \%$ ) in men, and $43 \%$ ( $95 \%$ CI, $36 \%$ to $50 \%$ ) in women, with a false-positive rate of $33 \%$ (95\% CI, $22 \%$ to $44 \%$ ) in men and $46 \%$ ( $95 \%$ CI, $37 \%$ to $55 \%$ ) in women, with no significant differences noted.

\section{Occupational Injury}

As shown in Table 2, there were 79 patients with occupational injury, with 160 patients in the gradual-onset group. The prevalence of facet joint pain as $28 \%$ (95\% CI, $18 \%$ to $38 \%$ ) in the occupational injury group compared to $44 \%$ ( $95 \%$ CI, $36 \%$ to $52 \%$ ) in the gradual-onset group which was statistically significant, with a false-positive rate of 
Table 1. Evaluation of influence of gender: Comparsion of the results of facet joint nerve block's (single blocks with lidocaine and double blocks with lidocaine and bupivacaine)

\begin{tabular}{|c|c|c|c|c|}
\hline & \multicolumn{2}{|c|}{$\begin{array}{c}\text { Single Block } \\
\text { Men (121) }\end{array}$} & \multicolumn{2}{|c|}{$\begin{array}{l}\text { Double Blocks } \\
\text { Women (199) }\end{array}$} \\
\hline & Positive & Negative & Positive & Negative \\
\hline Positive & 46 & 25 & 86 & 52 \\
\hline Negative & & 50 & & 61 \\
\hline Prevalence & \multicolumn{2}{|c|}{$38 \%(95 \%$ CI $29 \%$ to $47 \%)$} & \multicolumn{2}{|c|}{$43 \%(95 \%$ CI $36 \%$ to $50 \%)$} \\
\hline False positive rate & \multicolumn{2}{|c|}{$33 \%(95 \%$ CI $22 \%$ to $44 \%)$} & \multicolumn{2}{|c|}{$46 \%(95 \%$ CI $37 \%$ to $55 \%)$} \\
\hline Specificity & \multicolumn{2}{|c|}{$67 \%(95 \%$ CI $56 \%$ to $78 \%)$} & \multicolumn{2}{|c|}{$54 \%(95 \%$ CI $45 \%$ to $63 \%)$} \\
\hline
\end{tabular}

$28 \%(95 \% \mathrm{CI}, 16 \%$ to $40 \%)$ in the occupational injury group and $46 \%$ (95\% CI, 36\% to $56 \%$ ) in the gradualonset group.

\section{Smoking}

Only nonsmokers and heavy smokers with greater than 30 pack years of smoking history were evaluated. Ninetytwo patients were nonsmokers, compared to 74 who were heavy smokers. Patients who had a history of less than 30 pack years of smoking and previous heavy smokers, who were currently not smoking were not included. The results showed (Table 3 ) that there was no significant difference in the prevalence of facet joint pain in chronic low back pain among these groups, with $43 \%$ (95\% CI, 33\% to $53 \%$ ) of prevalence in the nonsmoker group, compared to $41 \%$ (95\% CI, $30 \%$ to $52 \%$ ) in the heavy smoker group, with false-positive rates of $46 \%$ (95\% CI, $32 \%$ to $60 \%$ ) and $39 \%$ (95\% CI, $25 \%$ to $53 \%)$.

\section{DISCUSSION}

Many epidemiologic studies have focused on risk factors for low back pain, attempting to evaluate occupational, nonoccupational, and psychosocial factors in order to analyze the various risk factors of low back pain. Determinants of low back pain include physical factors, social demographic characteristics, individual factors, habits, poor general health; and psychosocial factors. Among these, occupational injury, gender, and smoking are considered significant.

Occupational low back pain in industry is a major problem. State-by-state surveys in the United States show that

Table 2. Evaluation of influence of occupational injury: Comparison of the results of facet joint nerve block's (single blocks with lidocaine and double blocks with lidocaine and bupivacaine)

Occupational Injury (79)

Double Blocks

Single Blocks

Positive

Negative

Prevalence

False positive rate

Specificity

Positive

16

41

$72 \%(95 \%$ CI $60 \%$ to $84 \%)$
Gradual Onset (160)

Double Blocks

Negative

$28 \% *(95 \%$ CI $18 \%$ to $38 \%)$

$28 \% *(95 \%$ CI $16 \%$ to $40 \%)$
Positive

70

49

$44 \%(95 \%$ CI $36 \%$ to $52 \%)$

$46 \%(95 \%$ CI $36 \%$ to $56 \%)$

$54 \%(95 \%$ CI $44 \%$ to $64 \%)$

\footnotetext{
* Indicates significant difference
} 
Table 3. Evaluation of influence of smoking: Comparsion of the results of facet joint nerve block (single blocks with lidocaine and double blocks with lidocaine and bupivacaine)

\begin{tabular}{|c|c|c|c|c|}
\hline \multirow[b]{2}{*}{ Single Blocks } & \multicolumn{2}{|c|}{$\begin{array}{c}\text { Non-smoker (92) } \\
\text { Double Blocks }\end{array}$} & \multicolumn{2}{|c|}{$\begin{array}{c}\text { Heavy smokers (74) } \\
\text { Double Blocks }\end{array}$} \\
\hline & Positive & Negative & Positive & Negative \\
\hline Positive & 40 & 24 & 30 & 17 \\
\hline Negative & & 28 & & 27 \\
\hline Prevalence & \multicolumn{2}{|c|}{$43 \%(95 \%$ CI $33 \%$ to $53 \%)$} & \multicolumn{2}{|c|}{$41 \%(95 \%$ CI $30 \%$ to $52 \%)$} \\
\hline False positive rate & \multicolumn{2}{|c|}{$46 \%(95 \%$ CI $32 \%$ to $60 \%)$} & \multicolumn{2}{|c|}{$39 \%(95 \%$ CI $25 \%$ to $53 \%)$} \\
\hline Specificity & \multicolumn{2}{|c|}{$54 \%(95 \%$ CI $40 \%$ to $68 \%)$} & \multicolumn{2}{|c|}{$61 \%(95 \%$ CI $47 \%$ to $75 \%)$} \\
\hline
\end{tabular}

occupational low back pain constitutes $9 \%$ to $26 \%$ of all industrial insurance claims and $26 \%$ to $42 \%$ of all wagereplacement and health-care costs (23). The rate of low back pain associated with high physical demands at work is high in the United States (24-26), even though Murphy and Bolinn (27) reported that the US estimate rate of annual low back pain claims decreased 34\% between 1987 and 1995, while the annual low back pain claims costs during the same time decreased $58 \%$.

Health statistics routinely demonstrate that women have a higher morbidity from acute and nonfatal diseases than men do. Indeed, in most epidemiological pain research, women are more likely than men to report a variety of temporary and persistent pains in addition to moderate or severe pains from menstruation, pregnancy, and childbirth (28). However, only small gender differences were reported in the majority of epidemiological investigations of the prevalence of low back pain (29). While many studies $(28,30$ 36) reported higher rates of incidence of low back pain in women, some studies found that men reported more low back pain at the time of the interview than women (37, 38). However, in spite of these differences in reporting, it appeared that the prevalence of back pain may be more strongly related to occupational factors than to gender (39).

Approximately $26 \%$ of all the adults in the United States smoke, and recent estimates suggest that prevalence is increasing in youth. In an experimental animal study, Holm and Natchemson (40) suggested that cigarette smoking not only significantly affects the circulation outside the intervertebral disc, where the most pronounced effect is the reduction in solute-exchange capacity, but also significantly deteriorates the cellular uptake rate and metabolic production within the disc. Hambly and Mooney (41) reported that cigarette smoking will create a reduced $\mathrm{pH}$ in the rabbit's intervertebral disc. Battie et al (42) showed that disc degeneration was $18 \%$ greater in the lumbar spine in smokers compared with identical twins who were nonsmokers. Leboeuf-Yde (43) conducted a systematic review of the epidemiologic literature on smoking and low back pain in which he reviewed 47 epidemiologic studies from 41 journal articles, published between 1974 and 1996, showing no consistency of statistically significant positive associations between smoking and low back pain. However, she also showed that the association, when present, was usually weak and clearly apparent only in large study samples. A statistically significant positive association with smoking was reported for $34 \%$ of the 97 low back pain variables in cross-sectional studies and for $35 \%$ of the 26 low back pain variables in longitudinal studies. This analysis showed consistent evidence of a causal link between smoking and low back pain only in the study with the largest sample. Thus, smoking is considered as a risk factor and not a cause of low back pain, and it is a weak risk factor.

The results of our study showed no significant difference between men and women with a prevalence of facet joint pain, smokers, and nonsmokers; but it showed significantly lesser prevalence of facet joint pain in patients sustaining occupational injuries. Thus, these results indicate and confirm previous evaluations by Schwarzer et al $(12,15)$ showing lower prevalence of facet joint pain in patients after the injury.

We may be criticized for using controlled, comparative local anesthetic blocks of facet joint nerves instead of placebo-controlled diagnostic blocks, or intra-articular injections for facet joint pain. However, one of the reported 
drawbacks of local anesthetic control is that comparative local anesthetics may not be implementable for intra-articular blocks because it is not known whether the placement of local anesthetic in a relatively avascular environment such as a joint space affects its expected duration of action. Thus, we employed medial branch blocks utilizing comparative local anesthetic agents in all cases. Placebocontrolled blocks are not feasible in practice settings in the United States.

We may be criticized for our sample selection including two previous studies. We felt that a large sample would provide better data than comparison of each factor individually in small groups of patients.

\section{CONCLUSION}

The results of this study showed that the facet joint is the common pain generator in chronic low back pain, with no significant difference noted based on gender, on smoking, but with significant difference noted with occupational injury compared to gradual onset of low back pain, with $28 \%$ prevalence of facet joint pain in occupational injury patients compared to $44 \%$ in the gradual onset group.

\section{REFERENCES}

1. Kuslich SD, Ulstrom CL, Michael CJ. The tissue origin of low back pain and sciatica: A report of pain response to tissue stimulation during operation on the lumbar spine using local anesthesia. Orthop Clin North Am 1991; 22:181-187.

2. Bogduk N (ed). Low back pain. Clinical anatomy of lumbar spine and sacrum, ed. 3. Churchill Livingstone, New York, 1997; pp 187-213.

3. Goldthwait JE. The lumbosacral articulation: An explanation of many cases of lumbago, sciatica, and paraplegia. Boston Med and Surg J 1911; 164:365372.

4. Putti V. Lady Jones' lecture on new concepts in pathogenesis of sciatic pain. Lancet 1927; 2:53-60.

5. Ghormley RK. Low back pain. With special reference to the articular facets, with presentation of an operative procedure. JAMA 1933; 101:1773-1777.

6. Badgley CE. The articular facets in relation to low back pain and sciatic radiation. J Bone Joint Surg 1941; 23:481.

7. Hirsch D, Inglemark B, Miller M. The anatomical basis for low back pain. Acta Orthop Scand 1963; 33:1.

8. Mooney V, Robertson J. The facet syndrome. Clin Orthop 1976;115:149-156.

9. McCall IW, Park WM, O'Brien JP. Induced pain referral from posterior elements in normal subjects. Spine 1979;4:441-446.
10. Marks R. Distribution of pain provoked from lumbar facet joints and related structures during diagnostic spinal infiltration. Pain 1989;39:37-40.

11. Fukui S, Ohseto K, Shiotani M et al. Distribution of referral pain from the lumbar zygapophyseal joints and dorsal rami. Clin J Pain 1997;13:303-307.

12. Schwarzer AC, Aprill CN, Derby R et al. Clinical features of patients with pain stemming from the lumbar zygapophysial joints. Is the lumbar facet syndrome a clinical entity? Spine 1994; 19:1132-1137.

13. Manchikanti L, Pampati VS, Pakanati RR et al. Prevalence of facet joint pain in chronic low back pain. Pain Physician 1999; 2:59-64.

14. Manchikanti L, Pampati RR, Fellows B et al. The diagnostic validity and therapeutic value of medial branch blocks with or without adjuvants. Cur Rev Pain 2000; 4:337-344.

15. Schwarzer AC, Wang S, Bogduk N et al. Prevalence and clinical features of lumbar zygapophysial joint pain. A study in an Australian population with chronic low back pain. Am Rheum Dis 1995; 54:100-106.

16. Manchikanti L, Pampati VS, Fellows B et al. The inability of the clinical picture to characterize pain from facet joints. Pain Physician 2000; 3:158-166.

17. Manchikanti L, Singh V, Pampati V et al. Evaluation of the relative contributions of various structures in chronic low back pain. Pain Physician 2001; 4:308316.

18. Manchikanti L, Pampati V, Singh V et al. Evaluation of the role of facet joints in persistent low back pain in obesity: A controlled, prospective, comparative evaluation. Pain Physician 2001; 4:266-272.

19. Manchikanti L, Pampati VS, Baha A et al. Contribution of facet joints to chronic low back pain in postlumbar laminectomy syndrome: A controlled comparative prevalence evaluation. Pain Physician 2001; 4:175-180.

20. Manchikanti L, Pampati V, Rivera J et al. Role of facet joints in chronic low back pain in the elderly: A controlled comparative prevalence study. Pain Practice 2001; (4).1:1-6.

21. Manchikanti L, Pampati V, Fellows B et al. Influence of psychological factors on the ability to diagnose chronic low back pain of facet joint origin. Pain Physician 2001; 4:349-357.

22. Bogduk N. International Spinal Injection Society guidelines for the performance of spinal injection procedures. Part 1. Zygapophysial joint blocks. Clin J Pain 1997; 13:285-302.

23. Volinn E, Koevering DV, Loeser JD. Back sprain in industry. The role of socioeconomic factors in chronicity. Spine 1991; 16:542-548.

24. Cohen-Mansfield J, Culpepper WJ, Carter P. Nursing staff back injuries. Prevalence and costs in long-term care facilities. AAOHN J 1996; 44:9-17.

25. Fourtes LJ, Shi Y, Zhang M et al. Epidemiology of back injury in university nurses from review of work- 
ers' compensation records and a care-control survey. J Occup Med 1994; 36:1022-1026.

26. Klein BP, Jensen RC, Sanderson LM. Assessment of workers' compensation claims for back strains/sprain. J Occup Med 1984; 26:443-448.

27. Murphy PL, Volinn E. Is occupational low back pain on the rise? Spine 1999; 24:691-697.

28. Unruh AM. Gender variation in clinical pain experience. Pain 1996; 65:123-167.

29. Waddell G. Risk factors for low back pain. In Waddell G. (Ed) The Back Pain Revolution. Churchill Livingstone, Philadelphia, 1998; pp 85-102.

30. Manchikanti L. Epidemiology of low back pain. Pain Physician 2000; 3:167-192.

31. Andersson HI, Ejlertsson G, Leden I et al. Chronic pain in a geographically defined general population. Studies of differences in age, gender, social class, and pain localization. Clin J Pain 1993; 9:174-182.

32. Svensson HO, Andersson GBJ. Low back pain in forty to forty-seven year old men. I. Frequency of occurrence and impact on medical services. Scand J Rehabil Med 1982; 14:47-53.

34. Virta L, Ronnemaa T, Osterman Ket al. Prevalence of isthmic lumbar spondylolisthesis in middle-aged subjects from eastern and western Finland. J Clin Epidemiol 1992; 45:917-922.

34. Gyntelberg F. One year incidence of low back pain among residents of Copenhagen aged 40-59. Dan Med Bull 1974; 21:30-36.

35. Nagi SZ, Riley LE, Newby LG. A social epidemiology of back pain in a general population. J Chronic Dis 1973; 26:769-779.

36. Reisbord LS, Greenland S. Factors associated with self-reported back pain prevalence. A population-based study. J Chronic Dis 1985; 38:691-702.

37. Lavsky-Shulan M, Wallace RB, Kohout FJ et al. Prevalence and functional correlates of low back pain in the elderly. The Iowa 65+ Rural Health Study. J Am Geriatr Soc 1985; 33:23-28.

38. Laslett $\mathrm{M}$, Crothers $\mathrm{C}$, Beattie $\mathrm{P}$ et al. The frequency and incidence of low back pain/sciatica in an urban population. NZ Med J 1991; 104:424-426.

39. De Girolamo G. Epidemiology and social costs of low back pain and fibromyalgia. Clin J Pain 1991; 7:S1S7.

40. Holm A, Nachemson A. Nutrition of the intervertebral disc. Acute effects of cigarette smoking. An experimental animal study. Ups J Med Sci 1988; 93:9199.

41. Hambly MF, Mooney V. Effect of smoking and pulsed electromagnetic fields on intradiscal $\mathrm{pH}$ in rabbits. Spine 1992; 17:83-85.

42. Battie MC, Videman T, Gill K et al. Smoking and lumbar intervertebral disc degeneration. An MRI study of identical twins. Spine 1991; 16:1015-1021.

43. Leboeuf-Yde C. Smoking and low back pain. A systematic literature review of 41 journal articles reporting 47 epidemiologic studies. Spine 1999; 24:14631470.

44. Deyo RA, Tsui-Wu YJ. Descriptive epidemiology of low back pain and its related medical care in the United States. Spine 1987; 12:264-268.

45. Lawrence RC, Helmick CG, Arnett FC. Estimates of the prevalence of arthritis and selected musculoskeletal disorders in the United States. Arthritis \& Rheumatism 1998; 41:778-799. 